\title{
O lugar da Pedagogia em Spinoza
}

Luís Machado de Abreu

Universidade de Aveiro, Portugal

\section{Resumo}

Ao percorrermos as páginas das histórias da educação e da pedagogia não podemos ficar surpreendidos ao verificar que não existe nelas lugar para Spinoza. O que neste breve ensaio se vai tentar descobrir é que a questão pedagógica em geral e a do ensino da filosofia não são tratadas com desprezo pelo pensador de Amsterdão, nem em relação a elas existem sinais de indiferença. Pretende-se mostrar de que modo algumas atitudes do filósofo juntamente com tópicos do seu pensamento servem para explicar a ausência de efetiva preocupação com a temática pedagógica. No entanto, o sistema espinosano encerra princípios pedagógicos de primordial relevância para $\mathrm{O}$ processo educativo.

Palavras-chave: Spinoza (1632-1677); filosofia da educação; pedagogia.

\begin{abstract}
As we peruse the pages of the histories of education and pedagogy, we cannot be surprised when we verify that they don't reserve a place for Spinoza. The purpose of this short essay is to reveal that the pedagogical question, in general, and the question about the teaching of philosophy are not disdained by the thinker of Amsterdam, nor there is any sign of indifference about those questions. It is intented to show in what way some attitudes of the philosopher, along with topics of his thought, serve to explain the absence of an effective concern about the pedagogical theme. However, Spinoza's system comprehends pedagogical principles of primordial importance to the educative process.
\end{abstract}

Keywords: Spinoza (1632-1677); philosophy of education; pedagogy.

Filosofia e Educação - ISSN 1984-9605 - Volume 5, Número 1

Abril - Setembro de 2013 
- Ao percorrermos as páginas das histórias da educação e da pedagogia não podemos ficar surpreendidos ao verificar que não existe nelas lugar para Spinoza. Havemos de reconhecer que nem os interesses intelectuais do pensador, nem a atividade profissional de polidor de lentes o impeliam à elaboração de propostas com vista a modificar metas e procedimentos sedimentados ao longo de séculos pelas tradições de ensino/aprendizagem. Essas tradições tinham sido modeladas pela integração de elementos bebidos nas culturas clássicas, grega e latina, pelos valores religiosos de cada comunidade em que avultam as influências bíblicas e, no decurso dos séculos medievais, por marcas oriundas da mentalidade e costumes próprios dos diferentes povos.

Não deparamos em Spinoza com nada que reflita ou assinale, mesmo de longe, preocupações pedagógicas parecidas com as de contemporâneos, como Coménio ${ }^{1}$ (1592-1670), entre outros, nem tão pouco como as reflexões didáticas de Johannes Clauberg (1622-1665) na sua Logica Vetus et Nova (Amsterdam, 1654), obra existente na biblioteca de Spinoza. O silêncio sobre uma teoria da educação ou alguma proposta de plano pedagógico pode ser interpretado de muitas maneiras. Seria, no entanto, precipitado e excessivo ver nessa ausência um sinal de indiferença ou até de desprezo por tais questões.

O que neste breve ensaio se vai tentar descobrir e realçar é que a questão pedagógica em geral e a do ensino da filosofia não são tratadas com desprezo, nem em relação a elas existem sinais de indiferença. Muito pelo contrário. Seja como for, o patente défice de empenho do pensador de Amesterdão em assuntos relativos à educação tem levado os estudiosos interessados no tema a procurar razões de origem biográfica e de ordem doutrinal para essa ausência. No capítulo das razões doutrinais estão

\footnotetext{
${ }^{1}$ Johannes Amos Comenius é autor de vasta obra pedagógica de que fazem parte as Opera Didactica Omnia, publicadas no ano de 1657 em Amsterdam. Desta obra foi publicada em tradução portuguesa a Didáctica Magna - Tratado da arte universal de ensinar tudo a todos (COMÉNIO, 1976). O mesmo tradutor organizou a edição da Pampaedia - Educação Universal (COMÉNIO, 1971).
}

Filosofia e Educação - ISSN 1984-9605 - Volume 5, Número 1

Abril - Setembro de 2013 
frequentemente o antifinalismo e o determinismo fatalista. E não deixa de ser significativo que havendo a obra do pensador despertado tanto interesse na investigação filosófica das últimas cinco décadas, seja tão escasso o número de estudos consagrados a estas matérias.

Merecem referência dois estudos pioneiros. O primeiro ocupa-se de Spinoza como educador e tem por autor William Louis Rabenort (1911). Apresenta-se primariamente como contributo trazido à teoria da educação e só indiretamente como um estudo de filosofia. Desenvolve uma tentativa estimulante que consiste em inferir dos escritos sobre método, ética, política, alguns princípios e critérios capazes de aplicação ao campo educativo. O segundo trabalho é da autoria de Adolfo Ravà (1933) e ocupase da pedagogia de Spinoza. Reconhecendo que o necessitarismo constitui elemento nuclear da ontologia de Spinoza, um dado que limita o poder de o homem intervir sobre o seu próprio desenvolvimento, mostra também que existem amplas aberturas no sistema que possibilitam o aparecimento da temática pedagógica. E esforça-se mesmo por mostrar que as indicações educativas, além de porem em causa o determinismo absoluto do sistema tornam indiscutível a presença de elementos indeterministas na sua filosofia. Tanto Rabenort como Ravà consideram a componente pedagógica como algo de inerente à concepção ética de Spinoza e que só a brevidade da vida impediu que tivesse sido mais amplamente explicitada.

Com as notas de reflexão e comentário que se seguem pretende-se mostrar de que modo algumas atitudes do filósofo juntamente com tópicos do seu pensamento servem para explicar a ausência de efetiva preocupação com a temática pedagógica. E, no entanto, o sistema espinosano encerra princípios pedagógicos de primordial relevância para o processo educativo, além de se poder falar de prática pedagógica através da correspondência 
epistolar $^{2}$ e de a filosofia de Spinoza, tanto na Ética como nos tratados de política, se instituir como pedagogia da liberdade.

2. A existência de princípios pedagógicos na filosofia de Spinoza tanto decorre do conteúdo elaborado pela reflexão do filósofo sobre os procedimentos do entendimento humano e sobre a inteligibilidade da natureza como do percurso efectivo que foi por ele seguido na aquisição da ideia verdadeira. No primeiro caso, esses princípios devem procurar-se, como em sua matriz, nas proposições da Ética e nas reflexões de doutrina política contidas nos respetivos tratados. No segundo caso, os princípios encontram-se na concepção sobre o método proposta no Tractatus de Intellectus Emendatione (TIE) e no modo como o autor o pôs em prática.

Apelar para a prática na procura e construção do conhecimento foi precisamente o que fez Spinoza. Render-se à prática significa não fazer tábua rasa da experiência, perceber que é possível tirar dela ensinamentos para todo o tipo de situações, sejam as conveniências comuns da existência vulgar ou os problemas decisivos a que temos de responder nas grandes encruzilhadas da vida.

É com uma verificação de inequívoca natureza pedagógica que abre o TIE. Aí chama-se a atenção para o carácter fútil e vazio das coisas que mais frequentemente ocorrem na vida de todos os dias e procura-se ir para além do que encerram de limitado e frustrador, na mira de um bem verdadeiro que em vez de dececionar garanta uma existência feliz.

Se a experiência ordinária do homem comum nos mostra empenho infatigável na obtenção de riquezas, prazeres e honrarias, a lição que dela

\footnotetext{
${ }^{2}$ Na carta de 30 de março de 1673 a J. Ludwig Fabritius, ao declinar o convite para ensinar filosofia na Universidade de Heidelberg, Spinoza confirmou a preferência por produzir filosofia, em vez de se entregar à tarefa de a transmitir como docente. Na correspondência epistolar revela-se um investigador incansável e intransigente na solicitude pela verdade, muito mais investigador do que professor. Nesse sentido, ao referir as respostas de Spinoza aos diversos correspondentes, escreve Rovere (2010, p. 7): "Ces réponses ne sont pas celles d'un maitre dispensant son enseignement, mais celles d'un homme construisant sa pensée dans la pensée des autres, avec leurs mots."
}

Filosofia e Educação - ISSN 1984-9605 - Volume 5, Número 1

Abril - Setembro de 2013 
retira o filósofo é que as vantagens alcançadas por esse caminho são ilusórias e jamais permitem aceder à felicidade suprema. Rejeitada essa prática de desfecho frustrante, a decisão de seguir por outro caminho, o caminho da ideia verdadeira, faz desta nova experiência o exemplo ou modelo que convém imitar. Para podermos lá chegar temos de usar de todos os meios eficazes para termos êxito nesse projeto. O inventário de quais sejam os instrumentos adequados e a maneira de os utilizar com proficiência é o que o TIE tenta fornecer enquanto doutrina do método. Realizar todas as etapas propostas garante que se alcance plenamente o estado de natureza humana perfeita apontada como meta (ut ad summam humanam [...] perfectionem perveniatur. TIE, $\S 16)^{3}$. É da ordem do conhecimento a perfeição da natureza humana. Consiste no "conhecimento da união que a mente tem com toda a natureza" (cognitionem unionis, quam mens cum tota Natura habet. TIE,§13). Acontece, no entanto, que o conhecimento dessa união não se esgota na operação intelectual que a ele conduz nem numa experiência teórica de mera inteligibilidade. Anda acompanhada de vários outros efeitos que se podem resumir na plenitude de realização do homem, realização várias vezes chamada felicidade (beatitudo). O bem supremo em que se cumpre o que de mais útil e perfeito se pode alcançar consiste, pois, no conhecimento da Natureza, isto é, Deus, ser perfeitíssimo, origem e causa de tudo, a Natura naturans de que trata a primeira parte da Ética.

Fica assim enunciado com clareza um princípio essencial que preside à elaboração do método e é determinante para o sistema espinosano no seu todo. Tudo quanto no sistema possa constar de relevante em matéria de educação, virá adicionar-se à delimitação aqui feita do princípio pedagógico

\footnotetext{
${ }^{3}$. A identificação das referências das obra sde Spinoza figura no corpo do texto e segue a convenção adoptada pelos Studia Spinozana, Würzburg, aqui sumariamente apresentada: $\mathrm{E}=$ Ethica; ex.1: E4A13=Ética, quarta parte, apêndice, capítulo 13; ex.2.: E5P4S=Ética, quinta parte, proposição 4, escólio. Ep=Epistolae; ex.: Ep47=Carta 47. TIE=Tractatus de Intellectus Emendatione; ex.: TIE§23=Tratado da Reforma do Entendimento, \$23 (segundo numeração dos parágrafos estabelecida por Bruder). TP=Tractatus Politicus; ex.: TP 1/6=Tratado Político, capítulo I, §6. TTP=Tractatus Theologico-Politicus; ex.: TTP 16/192=Tratado Teológico-Político, capítulo XVI, p. 192 (edição C. Gebhardt).
}

Filosofia e Educação - ISSN 1984-9605 - Volume 5, Número 1

Abril - Setembro de 2013 
por excelência, isto é, preparar o homem para a felicidade através do conhecimento da sua união harmoniosa com a Natureza. A este princípio que serve de norma à elaboração do método e à sua ordenação acresce a ideia igualmente pedagógica das dificuldades que é necessário vencer para se atingir a meta. $\mathrm{O}$ conhecimento pretendido reclama esforço e persistência de acordo com a sentença expressa no final da Ética: "tudo o que é excelente é tão difícil como raro" (omnia praeclara tam difficilia quam rara sunt. E5P42S). A atividade educativa fica desde já situada do lado do trabalho, do esforço empenhado e combativo a empreender, tanto pelo educando como pelo educador. E afasta-se radicalmente de concepções facilitistas e de pedagogias centradas no lúdico. ${ }^{4}$ Note-se, no entanto, que é inteiramente errado pretender transformar a teoria do método tal como se encontra desenvolvida no TIE em doutrina da educação. Procurar o método adequado para chegar ao conhecimento da ideia verdadeira é tarefa de natureza cognitiva inscrita num programa muito próprio de filosofia ${ }^{5}$ que interage com a tradição filosófica e lhe propõe novos horizontes. Esse estatuto reflexivo jamais foi rejeitado ou posto em causa no corpus espinosano, nem alguma vez o autor se propôs completá-lo ou aplicá-lo mediante um tratado de pedagogia. Mas isso não obsta a que esta filosofia, tão metodicamente estruturada ao serviço da descoberta e preservação do conhecimento verdadeiro, complemente a sua vertente gnosiológica com a vertente educativa empenhada em formar o homem livre e feliz. Alcança essa complementaridade ao desenvolver uma teoria pedagógica dos afetos como veremos mais adiante.

\footnotetext{
${ }^{4}$ As pedagogias do lúdico que veem no "jogo o modo de expressão mais vivo e a maneira mais apropriada para a criança se comportar no mundo" foram contestadas por vários educadores e filósofos entre os quais Hannah Arendt (1972, pp. 234-236).

${ }^{5}$ A. Koyré lembra que "é raro ver um tratado de lógica começar por uma exortação moral, mas nada é tão espinosista." E sublinha com ênfase essa ideia, insistindo que a filosofia de Spinoza e o método visam "dirigir os nossos pensamentos para realizar a nossa perfeição e encontrar a nossa felicidade." Vd. Spinoza (1974, p. 97).
}

Filosofia e Educação - ISSN 1984-9605 - Volume 5, Número 1

Abril - Setembro de 2013 
3. A presença de elementos educativos implícitos na configuração do TIE à maneira de protréptico não deve ser menosprezada. São elementos derivados da própria sinalização do tratado para que seja entendido como reforma ou correção do entendimento (emendatio intellectus). É uma compreensão que se traduz atrvés da amostragem e avaliação de diferentes projetos e experiências de vida.

A emendatio instaura um processo de intervenção sobre uma trajetória existencial, com o intuito de aperfeiçoar o que continua imperfeito, nele introduzindo correções, emendas, reformas. Preside a esse processo interventivo a procura do que é mais útil para o ser humano, isto é, a realização plena da sua natureza na verdade e na felicidade partilhadas com os outros homens. A esta luz, a emendatio, pelo objetivo que serve e pela função de aperfeiçoamento que exerce converge com o campo de procedimentos educativos e o princípio por eles proposto. $\mathrm{Na}$ emendatio, como na educação em geral, pratica-se a convicção de que o ser humano é perfectível. O TIE, como sugere o título, reconhece essa perfectibilidade no plano do entendimento.

Livro programático, o TIE, além de expor o método para podermos progredir na descoberta e conhecimento da verdade, aponta alguns dos principais elementos do que vai ser o sistema de filosofia de Spinoza. De entre esses elementos, merece que se atente na ponderação e escolha de uma prática de vida que ocupa a atenção nos primeiros parágrafos do tratado.

Sob o signo da experiência adquirida e a adquirir deparamos com dois projetos de vida autónomos mas inteiramente opostos, e com um conjunto provisório de regras de vida. A existência do homem comum faz da procura de riquezas, honras e prazeres libidinosos o seu projeto de vida. Dele se ocupam os doze primeiros parágrafos. $\mathrm{O}$ fracasso previsível deste modelo de existência desencadeia a procura de outra via, a do projeto de realizar a perfeição da natureza humana. Alguns elementos desta nova via encontramse nos parágrafos treze a dezasseis. Quanto ao que foi designado como 
conjunto provisório ou intercalar de regras de vida, vem apresentado no parágrafo dezassete.

Os dois primeiros projetos já foram descritos mais acima em suas linhas gerais e acentuámos com clareza o caráter antitético que os separa. A escolha da via de realização da natureza humana perfeita representa um corte decidido com o estilo de vida precedente, corte que na esfera da vida religiosa se chama conversão. Só essa rutura com os bens apreciados pela vida comum e tomados como fim em si mesmos, acompanhada da firme decisão de enveredar pela laboriosa aquisição da verdade e do bem supremo, garantem o êxito desse projeto. Dele faz igualmente parte que nos esforcemos por conseguir que muitos mais conheçam como nós a verdade e alcancem a felicidade. Para que se forme essa sociedade devemos recorrer ao contributo de saberes tão variados que vão da filosofia moral à medicina e à mecânica. Entre eles, conta-se a "doutrina da educação das crianças". E ainda que não tenha deixado informação sobre os conteúdos e regras de aplicação, é revelador que tenha explicitado como considera importante a pedagogia e, ao mesmo tempo, deixe implícito que não se encontra aí nenhum núcleo merecedor de particular atenção e estudo de sua iniciativa. Sucede, no entanto, que quem se empenha a fundo por alcançar a meta da verdade e do bem supremo tem de contar com um caminho, duro e esforçado, e não com facilidades. Ora, ao lado dos que apostam nesse projeto, muitos há que não acatam devidamente as lições da experiência (TIE, §1) e, por “fraqueza humana” (humana imbecillitas, TIE,§13), uns e outros não chegam a compreender a ordem e as leis da natureza.

Enquanto uns se esforçam por compreender e aperfeiçoar a natureza humana, procurando encontrar o reto caminho, e outros, incapazes disso, correm atrás de ilusões, seria bom que estes se juntassem aos primeiros, e uns e outros adotassem uma prática de vida sensata, ainda que provisória. Provisória, por ainda não serem suficientemente compreendidos os seus fundamentos. Um projeto assim coloca o viver quotidiano dentro de um 
horizonte de razoabilidade que o resgata dos malefícios e deceções causados pela entrega aos bens incertos, e o organiza enquanto o homem aprende a conhecer as leis da razão e a reger-se por elas. As principais regras que devem orientar entretanto a existência individual e social são falar de modo a ser compreendido pelo vulgo e a prepará-lo para escutar e aderir à verdade; tudo fazer para não criar obstáculos ao objetivo que se pretende atingir; desfrutar das comodidades e prazeres da existência, de modo a não pôr em risco a saúde; não correr atrás do dinheiro nem de outros bens a não ser na medida em que sejam necessários para manter a vida e a saúde, sem nunca fazer deles um fim; adotar os usos e costumes da sociedade contanto que não nos impeçam de alcançar a meta. (TIE, §17 [passim])

Estas normas de bem viver protegem a concórdia da vida quotidiana porque ensinam a resistir às ilusões tentadoras das honrarias, dos prazeres e das riquezas, e favorecem a vida em sociedade. São regras moralizadoras de grande alcance em termos pedagógicos. $\mathrm{O}$ seu caráter provisório significa que a respetiva normatividade é de natureza pragmática, por lhe faltar o conhecimento causal das leis naturais que a regem.

4. Pode parecer estranho que em obra tão articuladamente geométrica, como a Ética, ocupem os afetos um lugar tão central e decisivo na economia do sistema. O certo é que as partes terceira, quarta e quinta se ocupam da questão dos afetos com seus diferentes matizes e contextos temáticos. Dessa questão faz parte o estudo da origem e natureza dos afetos, do seu papel na vida de servidão a que as paixões sujeitam o homem e da realização da liberdade com amor, alegria e beatitude.

O lugar nuclear reservado aos afetos não só não contradiz nem desvaloriza a prevalência que a razão tem na reflexão de Spinoza como permite marcar a distância em relação à concepção cartesiana das paixões. $\mathrm{O}$ prefácio da terceira parte da Ética deixa bem claro que doutrinas como a de Descartes e de outros que entendem que o homem pode exercer domínio 
absoluto sobre os afetos não passam de habilidade intelectual com pouca correspondência na realidade das coisas.

A atenção prestada ao universo dos afetos em geral e ao das paixões não deve ser vista como transigência com as fragilidades e incertezas do comportamento passional para limitar os efeitos perniciosos que advêm do desgoverno da vida afetiva. Como se os afetos fossem um defeito, desvio ou vício da natureza a exigir correção. Em si mesmos, afetos e paixões são, afinal, um elemento da natureza humana. Pertencem-lhe e regem-se pelas mesmas leis gerais da natureza. Nem o homem é um império dentro do império universal, nem os afetos devem ser tratados segundo leis peculiares e distintas das que regem a máquina do universo. Daqui decorrem duas consequências. Não sendo um desvio ou defeito da natureza, mas parte do normal funcionamento da grande natureza, os afetos não devem ser detestados nem escarnecidos como fazem os que os desprezam, em vez de tentarem conhecê-los e explicá-los. E, depois, tendo os afetos as mesmas causas e obedecendo às mesmas leis naturais que as restantes coisas, Spinoza propõe que se lhes aplique igualmente o método geométrico, considerando "as ações e os apetites humanos como se se tratasse de linhas, superfícies e sólidos.” (E3Praef)

Ficam deste modo bem patentes duas tomadas de posição com implicações na esfera educativa. A primeira diz-nos sem ambiguidade que a razão que quer compreender e explicar não abdica de intervir no mundo caótico e obscuro em que se agita a vida afetiva. É uma intervenção que visa iluminar e compreender, sem ter a pretensão de assegurar domínio absoluto sobre as paixões, como vimos atrás. A segunda posição consiste em construir a inteligibilidade do mundo dos afetos recorrendo ao método dos geómetras já aplicado nas duas primeiras partes da Ética a Deus e à natureza da mente.

Sendo certo, como repetidamente afirma a Ética que na existência quotidiana do homem comum o tumulto das paixões perturba e impede que 
ele se deixe governar pelos imperativos da razão, fica em aberto o muito trabalho exigido para melhor conhecimento e mais adequado governo dos afetos por parte de cada indivíduo. Promover esse conhecimento e ensinar esse governo, nisso consiste a principal tarefa da pedagogia dos afetos. Mas como explicar que o conhecimento seja o grande e único remédio para governar os afetos e rejeitar, ao mesmo tempo, que a razão tenha domínio absoluto sobre eles? A resposta é dada sobretudo na quinta parte da Ética. No prefácio a esta parte encontramos a refutação do poder absoluto que a vontade exerceria sobre as emoções e afetos segundo os estoicos e Descartes.

É na concepção cartesiana acerca das relações entre a mente e o corpo que o autor da Ética se detém. Lembra a função de elo de ligação e de transmissão que nessa teoria desempenha a denominada glândula pineal, tanto para receber as sensações vindas do meio exterior e transmiti-las à mente como para produzir o movimento das paixões por determinação da vontade. O papel da vontade seria de tal modo decisivo que o espírito humano, desde que bem orientado, asseguraria poder absoluto sobre as paixões. É uma maneira de pôr a questão que Spinoza denuncia abertamente como obscura e à revelia do princípio cartesiano da evidência e do conhecimento assente em ideias claras e distintas.

Mas afastada a existência de poder absoluto da razão sobre os afetos, ficará excluída a capacidade de toda e qualquer intervenção intelectual na nossa vida afetiva? De modo nenhum. O poder da mente humana sobre os afetos existe efetivamente, mas trata-se de determinar de que modo ele se exerce e até onde pode chegar como remédio das paixões. A chave encontra-se na mente e na potência da razão que, habilitando-nos com conhecimento adequado feito de ideias claras e distintas nos fará compreender os afetos como elementos constitutivos da natureza do ser humano. Embora esse conhecimento não assegure domínio absoluto, pode no entanto estabelecer domínio parcial sobre os afetos na medida em que se

Filosofia e Educação - ISSN 1984-9605 - Volume 5, Número 1

Abril - Setembro de 2013 
empenha em conhecê-los. Do seu cada vez melhor conhecimento decorre o poder de os gerir de modo mais competente, aumentando a potência de agir e o conforto do contentamento.

Governar os afetos e domar as paixões é tarefa que depende do progresso que o homem pode e deve efetuar à medida que avança no conhecimento de si próprio e do lugar que ocupa no conjunto da natureza. Ora, conhecer-se é compreender que o homem é um ser de desejo, dado que "o desejo é a própria essência do homem enquanto concebida como determinada por uma afeção a fazer alguma coisa.” E3AD1 Esta afeção pode ter causas internas e também causas externas. A causa interna coincide com a própria natureza ou essência do homem enquanto a concebemos adequadamente como determinada a agir. Causas externas são todas as coisas independentes de nós que nos afetam aumentando ou diminuindo a potência de existir.

Sejam ações ou paixões, todos os afetos têm origem no desejo, isto é, na essência ou natureza humana. Neles opera como elemento determinante a mesma potência de desejar. O que os distingue, pois se trata de afetos diferentes, é o grau e fundamento do conhecimento em que se baseiam. Enquanto as ações são desejos com origem em ideias adequadas, as paixões nascem de causas exteriores e, por isso, de ideias inadequadas. Enquanto as paixões partem de conhecimentos truncados e confusos, as ações procedem de ideias claras e distintas, isto é, de conhecimento adequado.

Mas acontece que o remédio para as paixões está na procura de melhor conhecimento das causas que as produzem. E o avanço desse saber pode ser tão bem sucedido que conforme se afirma em E4P59: “A todas as ações a que somos determinados por um afeto que é uma paixão, podemos ser determinados sem ela pela razão.” Exemplo dado por Spinoza acerca desta situação é o comportamento de contágio social e imitação. Levados por uma disposição natural, desejamos que os outros vivam em conformidade com a nossa própria maneira de ser ou constituição (ingenium). A este desejo, 
quando o sujeito que o tem não vive sob o ditame da razão, chama-se ambição ou mesmo orgulho e é uma paixão. Se, pelo contrário, o sujeito movido por esse desejo vive sob a direção da razão, estamos então perante uma ação chamada piedade ou moralidade (pietas). Numa palavra, o desejo que nos determina a fazer alguma coisa, tanto pode ser útil e virtuoso, se acompanhado de conhecimento adequado, como nocivo e reprovável, quando oriundo de ideias inadequadas. (Cf. E5P4S) Diremos, em síntese, que esta pedagogia dos afetos encontra a sua consumação quando o comportamento humano se traduzir em potência de agir informada e consciente de si.

5. Um dos tópicos mais pertinentes no âmbito desta pedagogia é o que nos ensina a lidar com afetos que, pondo em perigo o nosso poder de existir, limitando-o, devem ser geridos de modo a evitar que produzam esse efeito. Fiel a uma doutrina segundo a qual a dinâmica afetiva assenta num sistema de forças em que as mais poderosas podem contrariar as forças mais fracas, afirma que "um afeto não pode ser refreado ou impedido a não ser por um afeto contrário e mais forte (fortiorem) que o afeto refreado.” (E4P7)

A transposição pedagógica desta conceção dinâmica dos afetos determinaria que se procedesse ao levantamento pormenorizado dos afetos, fazendo-o acompanhar dos seus correspondentes contrários e mais fortes. Não encontramos esse levantamento em Spinoza, apesar de depararmos com alguns casos pontuais dados como aplicação ou ilustração da doutrina. Uma das aplicações mais consequentes desta gestão da vida afetiva é a que ele faz à esfera política. $\mathrm{Na}$ origem do Estado encontra-se o sentimento de medo que afeta o homem ao saber-se fraco e impotente para enfrentar a violência do caos e da guerra quando se trata de garantir a sobrevivência. O Estado proporciona aos cidadãos a vitória sobre o medo, porque os cidadãos transferiram para ele a potência de cada um e esperam que ele, detentor do poder soberano, o exerça com leis aptas a garantir segurança e a permitir a 
liberdade. A organização política coroada pelo poder do Estado institui a esperança de viver em segurança, paz e liberdade como paixão mais forte do que o medo.

Além do poder dos afetos mais fortes, há que contar sempre com o poder do conhecimento que podemos obter sobre eles. Veja-se, por exemplo, a tristeza que acompanha a perda de um bem estimado. Não conseguiremos evitá-la completamente. Todavia, a dor ou tristeza será em grande parte mitigada se compreendermos que não podíamos de modo nenhum conservar esse bem tão estimável. (Cf. E5P6S)

6. Saber habitar a terra e cuidar da natureza tornou-se preocupação insistente de que nenhum ser humano responsável se pode alhear tanto no plano individual como no coletivo. Encontramos em Spinoza a compreensão profunda do que devem ser as bases filosóficas e éticas desse sentido de encontro e comunhão integradora na dinâmica da natureza. Não se trata de atribuir ao filósofo do século XVII o levantamento de questões e respostas para o crescimento descontrolado, a depredação selvagem dos recursos ou a poluição galopante. Seria puro anacronismo. Situação bem diferente é reconhecer o contributo inovador que ao espírito ecológico traz o sistema espinosano por nele se encontrarem elementos construtivos de uma pedagogia da relação do homem com o ambiente

O primeiro e mais fundamental desses elementos é a metafísica monista sobre a qual está edificada a doutrina exposta na Ética acerca de Deus ou Natureza, acerca do homem e seus afetos, e ainda acerca da liberdade. A concepção de que há uma só substância com um número infinito de atributos, de tal modo que tudo quanto existe são modos, isto é, "afeções da substância, ou seja, o que existe noutra coisa graças à qual é também concebido" (E1Def5) estabelece um estreito vínculo de interconexão de cada modo com a substância e dos modos entre si. Temos aqui o fundamento da abordagem holística que deve ser seguida tanto na

Filosofia e Educação - ISSN 1984-9605 - Volume 5, Número 1

Abril - Setembro de 2013 
análise teórica dos problemas ambientais como na preparação de deliberações relativas a ações a empreender. Homens e demais seres têm por essência a condição de partes de um todo a que pertencem. Não podem, por isso, ser pensados senão como interdependentes em si mesmos e dependentes do todo de que são modos. Esse todo é a substância na qual e por meio da qual são concebidos. Chegamos assim ao enunciado ontológico de pressupostos do imperativo contemporâneo que nos incita a "pensar de modo global e a agir localmente", ao mesmo tempo que nos convida a rejeitar padrões de pensamento e de ação inspirados por uma visão do mundo atomística e individualista.

Outro contributo de Spinoza para a pedagogia da consciência ecológica está na sábia articulação do segundo e do terceiro géneros de conhecimento. O segundo género de conhecimento é o conhecimento elaborado pela razão que encontra em si mesma o critério do conhecimento verdadeiro, adequado, feito de ideias claras e distintas. Este conhecimento manifesta-se na filosofia e na ciência. $O$ terceiro género é o conhecimento intuitivo, unificador, em que são assumidas e aprofundadas duas ordens de conexão: a conexão das partes com o todo que é Deus/ Natureza, e a impregnação afetiva da razão enquanto amor intellectualis. No que à questão ecológica diz respeito, a lição de Spinoza consiste em realçar o papel de primeira importância que devemos esperar do conhecimento científico e da gestão racional dos bens naturais, sem cair em condenações sumárias da racionalidade científica por causa de utilizações indevidas que dela possam ser feitas. O que se impõe não é desacreditar a ciência e a razão mas fazer do conhecimento intuitivo a fonte de sabedoria que orienta e conduz o homem que vive segundo as leis da razão à plenitude da harmonia e da felicidade.

Dos dados colhidos decorre que se adote um estilo de vida simples, respeitador da natureza e dos outros seres humanos, saboreando as alegrias e 
os prazeres da existência, sem excessos, e fazendo da utilização frugal dos recursos disponíveis critério de bem viver.

7. Se considerarmos a tarefa pedagógica de instruir e de que modo ela foi aflorada por Spinoza, devemos afirmar, recorrendo a Platão (Sofista, 229, cd), que ele praticou um ensino paidêutico, isto é, dedicado a corrigir ou emendar preconceitos, crenças vulgares e falsas, e não tanto a preencher o vazio de mentes ignorantes. Assim sucedeu por causa do enraizamento social e histórico dos respetivos destinatários que nunca eram mentes virgens, mas espíritos moldados por experiências percetivas e por opiniões difundidas na sociedade a que pertenciam.

O método em Spinoza não diz respeito ao caminho que se deve seguir na transmissão de conhecimentos, mas no modo de os descobrir e deles nos apropriarmos. Não ensina saberes já adquiridos a quem os desconhece. Pratica a arte de caminhar do que só vagamente se conhece para o conhecimento verdadeiro. Não tem a natureza de didática, mas essencialmente a de heurística. A educação concebe-se desse modo como caminho que nos leva de nós até nós, através do conhecimento que assegura o trânsito da ilusão e do erro à verdade, do regime das paixões ao governo da razão, da servidão à liberdade.

O sentido do todo aplicado à ideia de educação fez de Spinoza um opositor da educação reduzida ao adestramento ou à especialização sem horizonte global. Confinado à especialização, o formando adquire eficiência robótica e vê ser-lhe negada a fruição harmoniosa da sua condição de homem. Lembremos que esta perspetiva não é posta em causa quando o filósofo se refere à realidade do "agir da alma segundo leis determinadas, à semelhança de um autómato espiritual" (quasi aliquod automa spirituale. TIE,§85). Pelo contrário, a evocação do autómato espiritual reforça a vinculação da atividade humana ao todo da Natureza cujas leis são também 
as leis do agir humano, ao invés da lei da vontade e do livre arbítrio defendida por Descartes.

O modelo educativo que aqui foi sendo sugerido é o do sábio, como decorre do papel atribuído ao conhecimento na integração do homem na natureza. Mas tal não equivale a dar cobertura ao elitismo nem ao individualismo solipsista. Só é realmente sábio quem cuida de colaborar na promoção dos outros para que o maior número participe na comunidade de quantos se regem pelas luzes da razão.

\section{Referências bibliográficas}

ARENDT, H. La crise de la culture. Huit exercices de pensée politique. Trad. de Patrick Lévy. Paris, Galimard/Idées, 1972.

COMÉNIO, J. Didáctica Magna - Tratado da arte universal de ensinar tudo a todos. Tradução e notas de Joaquim Ferreira Gomes. Lisboa, Fundação C. Gulbenkian, $1976^{2}$. Pampaedia (Educaşão Universal). Tradução e notas de Joaquim Ferreira Gomes. Coimbra, Facurldade de Letras da Universidade de Coimbra, 1971.

RABENORT, W. L., Spinoza as Educator. N.Y., Teachers College, Columbia University, 1911.

RAVÀ, A. "La pedagogia di Spinoza", in: Septimana Spinozana Acta Conventus Oecumenici in Memoriam Benedicti de Spinoza. Hagae Comitis, M. Nijhoff, 1933, pp.195-207.

ROVERE, M. "Présentation". In: SPINOZA, B. Correspondance. Présentation et traduction par Maxime Rovere. Paris, Flammarion, 2010.

SPINOZA, B. Traité de la Réforme de l'Entendement. Texte, trad. et notes de A. Koyré. 5ème éd. Paris, Vrin, 1974,

Opera, im Auftrag der Heidelberger Akademie der Wissenschaften herausgegeben von Carl Gebhardt, Heidelberg, Carl Winters Universitætbuchhandlung, 1972, 4 v. 